\title{
Application MuTsunami in Mentawai Island Indonesia
}

\author{
Muslim Muin ${ }^{1}$, Izqi Yustina Ammylia Yusuf $^{1, *}$, and Hendra Achiari ${ }^{1}$ \\ ${ }^{1}$ Coastal Engineering Research Group, Faculty of Civil and Environmental Engineering, Institut Teknologi Bandung, Indonesia
}

\begin{abstract}
Software MuTsunami as research tool in Coastal Research Group Institut Teknologi Bandung, was applied to simulate propagation of tsunami and sediment transport in Mentawai. The Tsunami occurred in 25 October 2010, 21:42:22 (GMT +7). The hydrodynamic model was based on Non-Orthogonal curvilinear coordinate in spherical coordinate. The results of simulation were compared with observational data, which was collected by group of researcher from Institut Teknologi Bandung, Waseda University, and Yokohama National University. The agreement between the model and observational data are very good.
\end{abstract}

\section{Introduction}

Three dimensional ocean hydrodynamics model using non-orthogonal curvilinear coordinate technique, also known as boundary fitted technique, has been well developed [1-3], and was world widely applied to simulate ocean circulation, for example in New York Harbor [4], Cone Bay Western Australia [5], Bay of Fundy Canada [6], etc. Funded by the National Research Council Indonesia, Muin [7] further developed a model of Tsunami propagation using two-dimensional version of the non-orthogonal boundary fitted hydrodynamics model [1]. The propagation model is integrated with tsunami generation model in a Geographic Information System (GIS), and developed in windows system, named MuTsunami as in-house models in Coastal Engineering Research Group (CERG), Institut Teknologi Bandung (ITB). MuTsunami had been successfully applied for Aceh Tsunami [8].

The main advantage of the MuTsunami is that it can be run using affordable notebook. Since the model use semi-implicit technique, the time step is no longer restricted by courant number. Therefore the results of simulation can be obtained in few minute. Once the magnitude and position of earthquake is known, the results of simulation can be run and posted on internet in 15 minute.

The 25 October 2010 Mentawai tsunami earthquake (Mw 7.8) ruptured the shallow portion of the Sunda megathrust seaward of the Mentawai Islands, offshore of Sumatra, Indonesia, generating a strong tsunami that took 509 lives [9]. They iteratively adjusted the data weighting, rupture velocity, spacing, and lateral extent of the finitefault model grid in the joint inversion of the hr-GPS and teleseismic signals to reproduce the tsunami observations through modeling of nonlinear and dispersive ocean wave processes. The results of their simulation matched the observations. However this iterative approach is not practical in Mitigation which quick response is required.
This paper presents the results of simulation of MuTsunami for the case of Mentawai Tsunami on October 25, 2010. The results of model were compared with available observation [10].

\section{Methodology}

MuTsunami consist of four models:

1. Wave Generation (Near Field)

a. Simple energy approach

b. Specified the initial condition

2. Wave Propagation (Far Field)

3. Wave Run-up

4. Sediment Transport Model

The propagation and sediment transport model use the non-orthogonal curvilinear coordinate technique in spherical coordinate. MuTsunami utilize the state of the art of three-dimensional sediment transport model MuSed3D [11] to simulate sediment movement by integrating over depth the basic equation to vertically averaged 2D sediment transport model.

\subsection{Tsunami generating model}

\subsubsection{Simple energy approach}

A large tsunami was caused by the movement of the sea floor. The best way to simulate the generation of Tsunami is to go back to the basic equations of conservation of mass and momentum (Navier-Stokes). Grilli and Watts [12] developed numerical model of Tsunami generation by submarine mass failure. This requires a dense grid systems and accurate data of seabed. Big rise in the sea floor is very difficult to predict accurately because it is highly dependent on mechanical or geotechnical characteristics of the seafloor in which data are very minimal. For these reasons and quick response and early warning data, MuTsunami use an empirical approach. The

\footnotetext{
* Corresponding author: izqiyustina@gmail.com
} 
empirical approach is to consider the potential energy of the water received from the energy generated by the quake would be a Tsunami Energy [13].

\subsubsection{Initial condition is specified}

Initially, the model was developed with a simple waveform generation models where the tsunami generation is derived by a simple empirical formula based on the energy of earthquake as described above. The latest version was developed to allow user use particular initial wave condition. However, the first approach is useful, for quick response.

\subsection{Wave propagation}

The wave propagation model (far field) requires the input of wave generation models (near field). The result of the wave generation model is the initial conditions of the wave propagation models. In this computational domain, a mathematical model was derived using vertically averaged long wave's equation in spherical coordinate. Non-orthogonal curvilinear coordinate technique [1-3, 14] was employed by neglecting the density gradient effect. The simulation results of the far field model are the input to Wave Run-up model.

Non-orthogonal Curvilinear Coordinate or also known as Boundary-Fitted technique is excellent model in areas with complex geometry. The advantage of NonOrthogonal Boundary Fitted Model is that the orthogonal grid system is not required. It is impossible to generate orthogonal grid in complex area. In Boundary-Fitted Techniques, a grid system is no longer square, the grid can be fitted to the shoreline. Use of the model with square grid will produce an error for the region with a complex geometry. Of course by using a smaller simulation grid size would minimize this problem, but this will require huge computer memory and CPU time.

The model use a spherical coordinate system as the basis of physical domain, meaning this model is much more accurate than the models using cartesian coordinate system given that our earth is not flat. Figure 1 illustrates the physical domain in spherical coordinate $(\phi, \theta)$ and computational domain in curvilinear coordinate $(\xi, \eta)$.

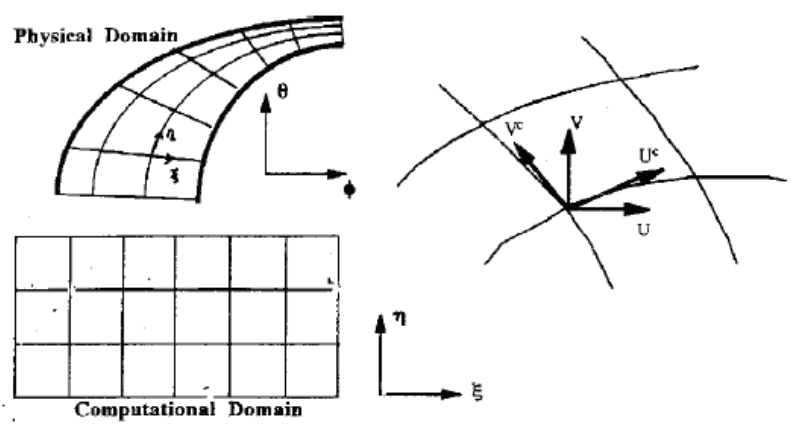

Fig. 1. Physical and Computational Domain of Non-Orthogonal Curvilinear Coordinate System [1]
Following Muin [1], after neglecting the density gradient effect, the governing equations in curvilinear coordinate system $(\xi, \eta)$, can be written as follows:

Conservation of Mass

$$
J R \cos \theta \frac{\partial \zeta}{\partial t}+\frac{\partial}{\partial \zeta}\left(\cos \theta J U^{c} D\right)+\frac{\partial}{\partial \eta}\left(\cos \theta J U^{c} D\right)=0
$$

Conservation of Momentum

$$
\begin{aligned}
& \begin{array}{l}
\xi \text { - Direction } \\
\frac{\partial^{c} D}{\partial t}
\end{array}=-\frac{\theta_{\eta} \theta_{\eta}+\cos ^{2} \theta \phi_{\eta} \phi_{\eta}}{J^{2} R \cos ^{2} \theta} D g \frac{\partial \zeta}{\partial \xi}+\frac{\theta_{\xi} \theta_{\eta}+\cos ^{2} \theta \phi_{\xi} \phi_{\eta}}{J^{2} \rho_{0} R \cos ^{2} \theta} D g \frac{\partial \zeta}{\partial \eta} \\
& \quad-\frac{\theta_{\eta}}{\mathrm{J}^{2} \cos ^{2} \theta}\left\{\left[\frac{\partial}{\partial \xi}\left(\phi_{\xi} \cos ^{2} \theta J U^{c} U^{c} D+\phi_{\eta} \cos ^{2} \theta J U^{c} V^{c} D\right)\right]\right. \\
& \left.+\left[\frac{\partial}{\partial \eta}\left(\phi_{\xi} \cos ^{2} \theta J U^{c} V^{c} D+\phi_{\eta} \cos ^{2} \theta J V^{c} V^{c} D\right)\right]\right\} \\
& +\frac{\phi_{\eta}}{\mathrm{J}^{2} R \cos ^{2} \theta}\left\{\left[\frac{\partial}{\partial x}\left(\theta_{\xi} \cos ^{2} \theta J U^{c} U^{c} D+\theta_{\eta} \cos ^{2} \theta J U^{c} V^{c} D\right)\right]\right. \\
& \left.+\left[\frac{\partial}{\partial \hbar}\left(\phi_{\xi} \cos ^{2} \phi J U^{c} V^{c} D+\theta_{\eta} \cos ^{2} \theta J V^{c} V^{c} D\right)\right]\right\} \\
& +\frac{\mathrm{fD}}{\mathrm{f} \cos \theta}\left[\left(\theta_{\xi} \theta_{\eta}+\cos ^{2} \theta \phi_{\xi} \phi_{\eta}\right) U^{c}+\left(\theta_{\eta} \theta_{\eta}+\cos ^{2} \theta \phi_{\eta} \phi_{\eta}\right) V^{c}\right] \\
& +\frac{\tau_{\mathrm{s} \xi}-\tau_{b \xi}}{\rho_{o}}
\end{aligned}
$$

$\eta$ - Direction

$$
\begin{aligned}
& \frac{\partial V^{c} D}{\partial}=-\frac{\theta_{\xi} \theta_{\xi}+\cos ^{2} \theta \phi_{\xi} \phi_{\xi}}{J^{2} R \cos ^{2} \theta} D g \frac{\partial \zeta}{\partial \eta}+\frac{\theta_{\xi} \theta_{\xi}+\cos ^{2} \theta \phi_{\xi} \phi_{\xi}}{J^{2} R \cos ^{2} \theta} D g \frac{\partial \zeta}{\partial \eta} \\
& +\frac{\theta_{\eta}}{\mathrm{J}^{2} \cos ^{2} \theta}\left\{\left[\frac{\partial}{\partial \xi}\left(\phi_{\xi} \cos ^{2} \theta J U^{c} U^{c} D+\phi_{\eta} \cos ^{2} \theta J U^{c} V^{c} D\right)\right]\right. \\
& \left.+\left[\frac{\partial}{\partial \eta}\left(\phi_{\xi} \cos ^{2} \theta J U^{c} V^{c} D+\phi_{\eta} \cos ^{2} \theta J V^{c} V^{c} D\right)\right]\right\} \\
& -\frac{\phi_{\xi}}{\mathrm{J}^{2} \cos ^{2} \theta}\left\{\left[\frac{\partial}{\partial \xi}\left(\phi_{\xi} \cos ^{2} \theta J U^{c} U^{c} D+\theta_{\eta} \cos ^{2} \theta J U^{c} V^{c} D\right)\right]\right. \\
& \left.+\left[\frac{\partial}{\partial \eta}\left(\phi_{\xi} \cos ^{2} \theta J U^{c} V^{c} D+\phi_{\eta} \cos ^{2} \theta J V^{c} V^{c} D\right)\right]\right\} \\
& -\frac{\mathrm{fD}}{\mathrm{J} \cos \theta}\left[\left(\theta_{\xi} \theta_{\xi}+\cos ^{2} \theta \phi_{\xi} \phi_{\xi}\right) U^{c}+\left(\theta_{\xi} \theta_{\eta}+\cos ^{2} \theta \phi_{\xi} \phi_{\eta}\right) V^{c}\right] \\
& +\frac{\tau_{\mathrm{s} \eta}-\tau b \eta}{\rho_{0}} \\
& \xi, \eta=\text { curvilinear coordinates } \\
& \phi, \theta=\text { longitude, latitude (degree) } \\
& \mathrm{t}=\text { time }(\mathrm{s}) \\
& \mathrm{f}=\text { Coriolis parameter } \\
& \mathrm{g}=\text { gravitational acceleration }\left(\mathrm{m} / \mathrm{s}^{2}\right) \\
& \zeta=\text { water surface deviation from mean level (m) } \\
& \mathrm{h}=\text { water depth }(\mathrm{m}) \\
& \mathrm{D}=\mathrm{h}+\zeta(\mathrm{m}) \\
& \mathrm{D}_{\mathrm{h}}=\text { horizontal eddy diffusivity }\left(\mathrm{m}^{2} / \mathrm{s}\right) \\
& \mathrm{R}=\text { earth's radius }(\mathrm{m}) \\
& \tau_{s}=\text { surface shear stress }(\mathrm{Pa}) \\
& \tau_{b}=\text { bottom shear stress }(\mathrm{Pa}) \\
& \mathrm{J}=\text { Jacobian }=\phi_{\xi} \theta_{\eta}-\phi_{\eta} \theta_{\xi}
\end{aligned}
$$


The above equation is written using incompressible flow assumption. Vertical acceleration is ignored (hydrostatic approximation).

As a boundary condition, the shoreline is considered as an impermeable layer where the water velocity in the direction perpendicular to the beach is zero. Radiation boundary is used along open boundary. On the surface of the water and the seabed, shear forces is determined by the quadratic shear stress formula.

The transformed vertically averaged equations are solved by semi-implicit technique, in which the water elevation in the wave equation is solved implicitly and the other explicit. Time step is no longer limited by the speed of wave propagation, so that the can be performed in more quickly and economically.

The computational is performed in a staggered grid system. Three-level time differencing is used to discretize the time domain to avoid artificial damping. The model had been tested to simulate standing wave in closed basin. The damping is negligible [7, 8]. A more detailed description of the three-dimensional version of this model is presented in Muslim Muin [1]. The ocean hydrodynamics model has been applied in worldwide.

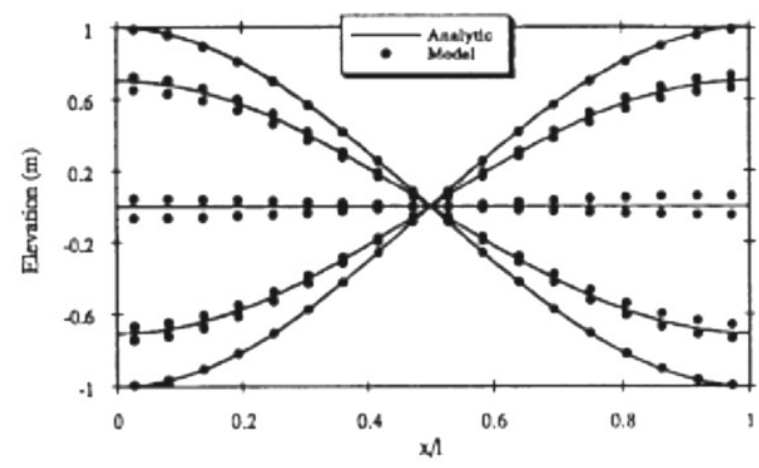

Fig. 2. Comparison of Model Predicted Surface Elevation with Analytic Solution for Standing Wave in Closed Basin at 1/8 Period Increment, $\mathrm{l}=23 \mathrm{~km}, \mathrm{~h}=10 \mathrm{~m}, \Delta \mathrm{t}=58 \mathrm{~s}$

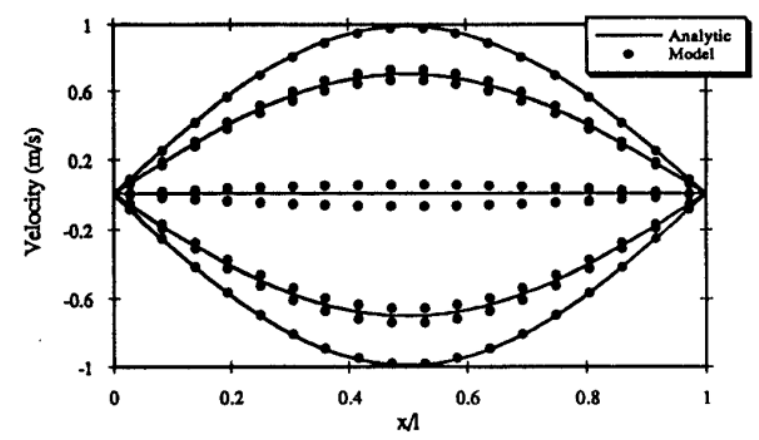

Fig. 3. Comparison of Model Predicted Velocities with Analytic Solution for Standing Wave in Closed Basin at 1/8 Period Increment, $\mathrm{l}=23 \mathrm{~km}, \mathrm{~h}=10 \mathrm{~m}, \Delta \mathrm{t}=58 \mathrm{~s}$

Figure 2 and Figure 3 present a comparison between the model prediction and analytic solution in the closed basin, with length of $23 \mathrm{~km}, 4 \times 18$ grid, water depth 10 $\mathrm{m}$. It shows that there is no numerical damping in the model which is very important in Initial Value Problem.

\section{Model Application for Mentawai Tsunami}

MuTsunami is applied to simulate for Mentawai Tsunami. The grid system is presented in Figure 4. It is finer in the interest area (West Sumatera Province) and coarser in others area. The grid size ranges from $5 \mathrm{~km}$ to $30 \mathrm{~km}$.

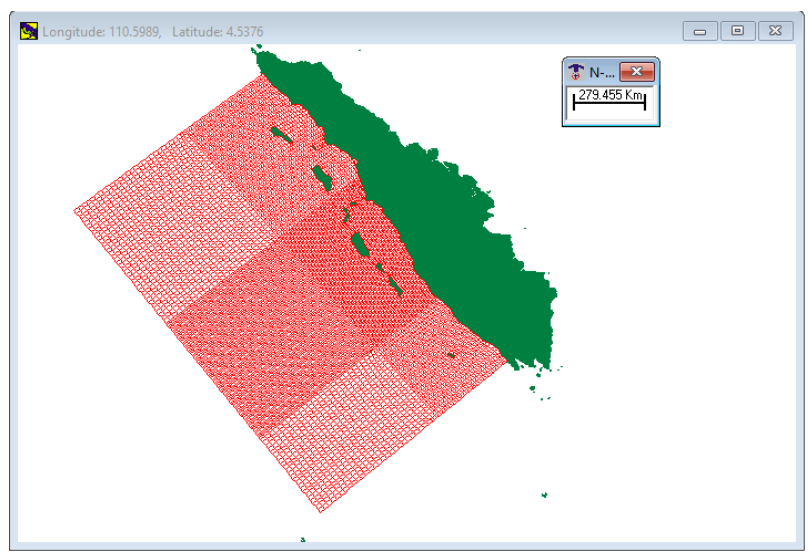

Fig. 4. Non-Orthogonal Curvilinear Coordinate Grid System in the Study Area

Figure 5 shows the water depth in the grid system. Bathymetric data was obtained from Geodas with one minute resolution. The water depth in the water cell is an averaged value of available data set.

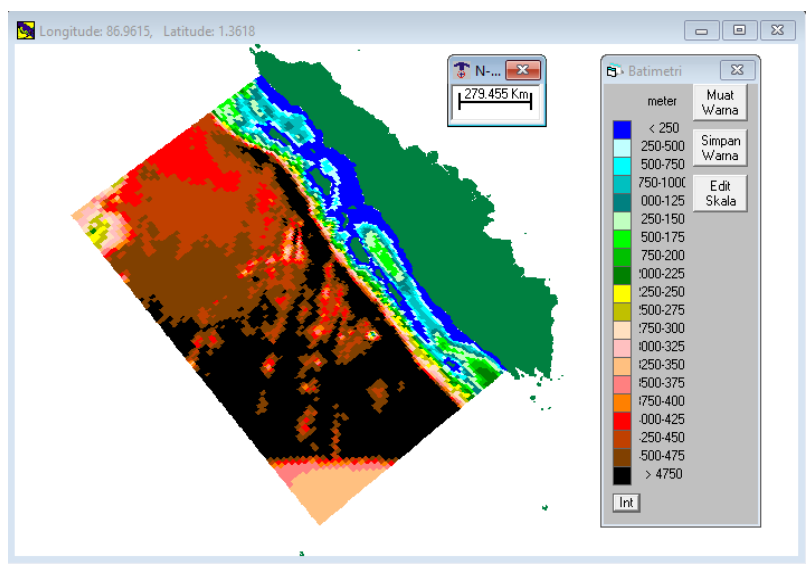

Fig. 5. Water depth data in the grid system

The model was run using; (1) simple energy approach for quick response mode, (2) specified Tsunami generation for better accuracy which is based on simulation by Han et. al, [9]. The computation was performed in affordable notebook computer, equipped with processor I5 $2.7 \mathrm{GHz}, 16 \mathrm{~GB}$ Ram. The time step is 5 seconds. The bottom friction was set 0.005 . The required CPU Time is less than one minute to complete 4 days simulation. 


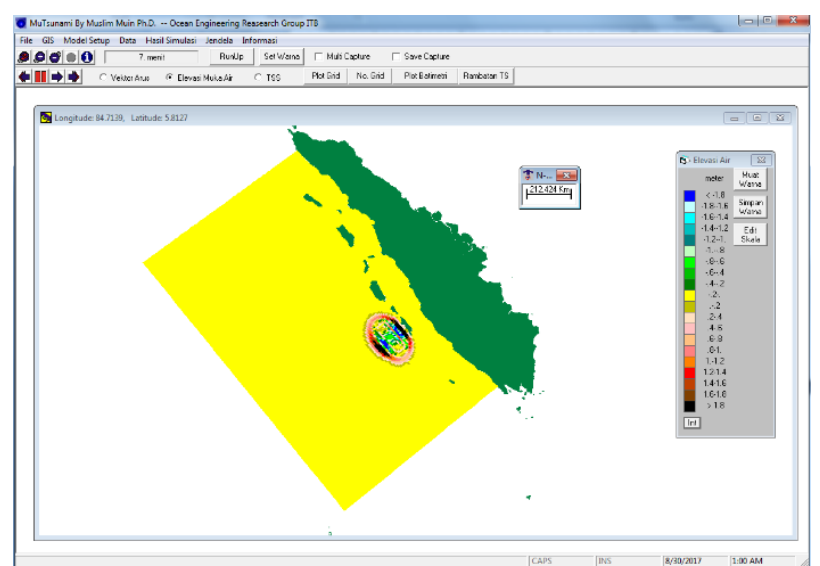

Fig. 6. Water elevation at 7 minute after earthquake, using Specified Tsunami Generation

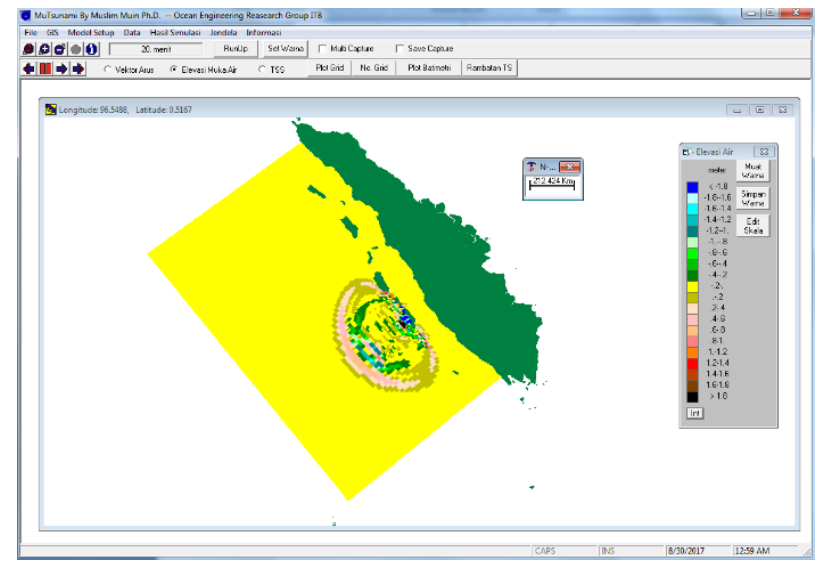

Fig. 7. Water elevation at 20 minute earthquake, using Specified Tsunami Generation

Figure 6 shows the predicted water elevation at 7 minute after the earthquake or when the big Tsunami hit Mentawai. Figure 7 presents the predicted water elevation at 20 minute. The Tsunami also propagate to Indian Ocean because of with small amplitude, less than one meter. The modelling results indicate the effectiveness of Mentawai Islands to protect West Sumatera from Tsunami.

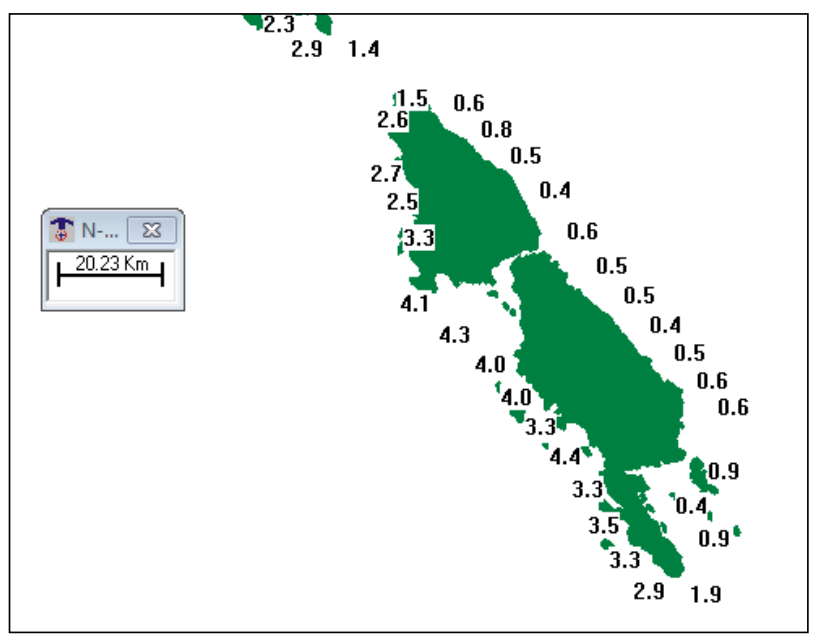

Fig. 8. Water elevation along the coast of Pagai Selatan Island, using Specified Tsunami Generation

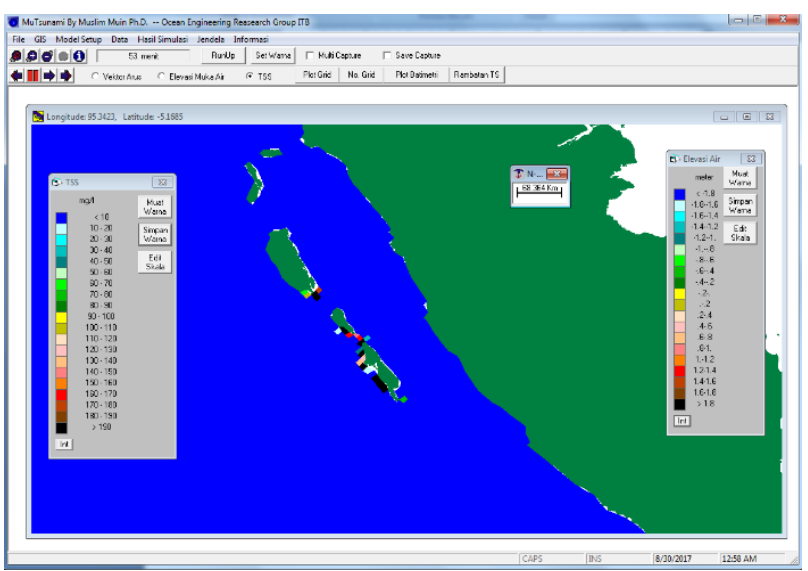

Fig. 9. Sediment Plume at 40 minute after earthquake

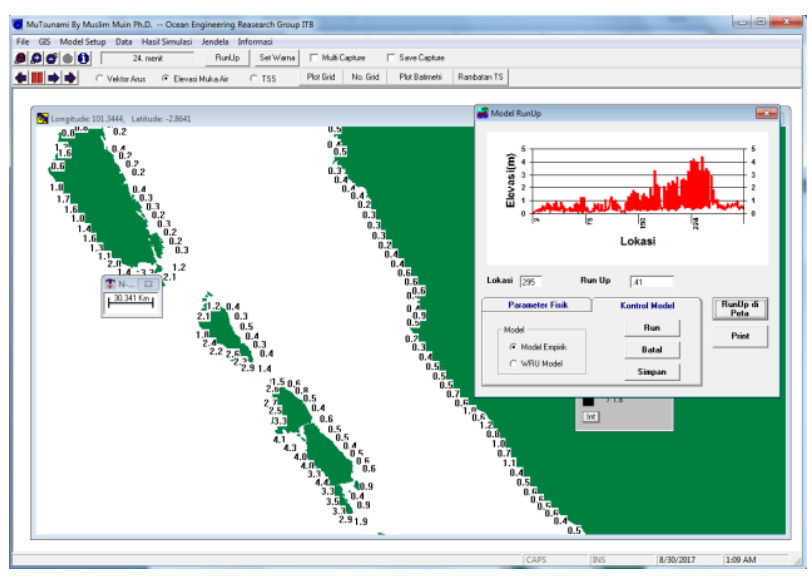

Fig. 10. Water elevation along the coast of West Sumatera Province and Mentawai Islands, the model was run using specified well known Tsunami Generation

Figure 8 presents the predicted maximum water elevation along the coast of Pagai Selatan Islands. Despite the simulation is conducted in relatively coarse grid system, the results of simulation is not much different from very high grid simulation by well known others model. The simulation can be completed in very short time and used as early warning system using affordable computer.

The model was also run to simulate one class of cohesionless sediment. The Erosion rate coefficient is specified $0.05 \mathrm{~mm} /$ hour, Critical Shear Stress for Erosion $=0.2 \mathrm{~Pa}$, and Critical Shear Stress for Deposition $=0.1$ $\mathrm{Pa}$. The settling velocity $=20 \mathrm{~mm} / \mathrm{sec}$. The results of simulation are presented in Figure 9. The model indicates that the seabed erosion in the area of Mentawai. It is because of the water current of Tsunami exceed the critical shear stress for erosion. The model also indicate that Tsunami will not erode the West Sumatera Coast.

Figure 10 shows the wave height along Mentawai Islands and along West Sumatera Coast. The results of simulation are comparable with field observation. The model clearly indicates that the coast of West Sumatera are well protected by Mentawai Islands.

Table 1 present the comparison between simulated wave height and observed wave height by Mikami [10]. 
Table 1. Comparison between results of simulation and observation.

\begin{tabular}{|c|c|c|c|c|}
\hline Location & $\begin{array}{c}\text { Latitu- } \\
\mathbf{d e}\end{array}$ & $\begin{array}{c}\text { Longitu- } \\
\mathbf{d e}\end{array}$ & $\begin{array}{c}\text { Simula- } \\
\text { tion (m) }\end{array}$ & $\begin{array}{c}\text { Observa- } \\
\text { tion (m) }\end{array}$ \\
\hline Bosua & -2.3664 & 99.8027 & 4.50 & 4.69 \\
\hline $\begin{array}{c}\text { Old- } \\
\text { Gobik }\end{array}$ & -2.3687 & 99.8212 & 4.80 & 5.69 \\
\hline Masokut & -2.3462 & 99.7883 & 4.40 & 4.42 \\
\hline $\begin{array}{c}\text { Bere- } \\
\text { Berilou }\end{array}$ & -2.3323 & 99.7289 & 4.30 & 3.18 \\
\hline
\end{tabular}

The main problem in the specified initial condition that the model is not linked into sophisticate model Tsunami Generation which requires higher resolution. Therefore, the use of simple energy approach to estimate the initial condition is not avoidable to get quick response.

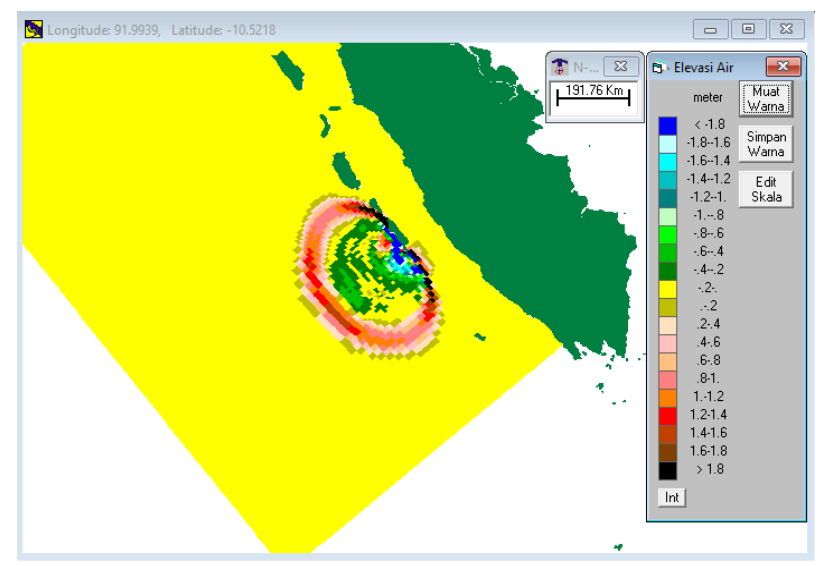

Fig. 11. Water elevation at 16 minute after earthquake, the model was run using Simple Energy Approach

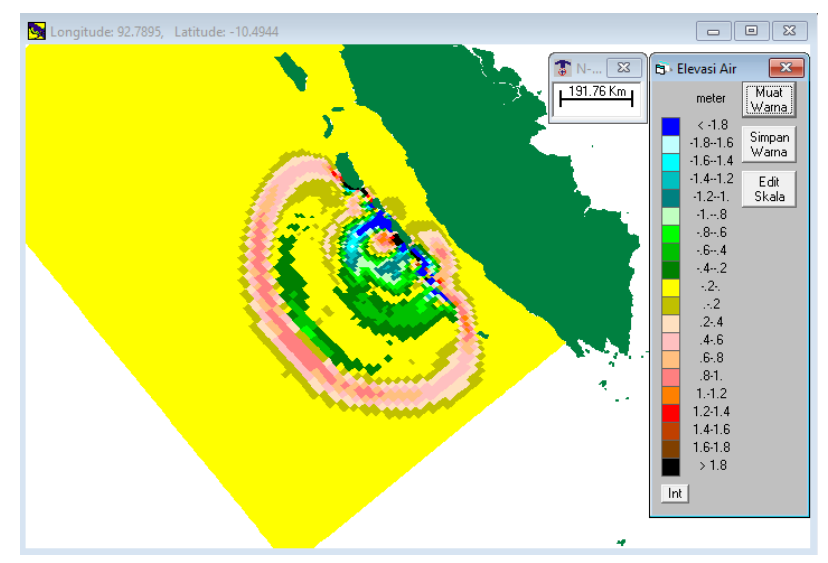

Fig. 12. Water elevation at 28 minute after earthquake, the model was run using Simple Energy Approach

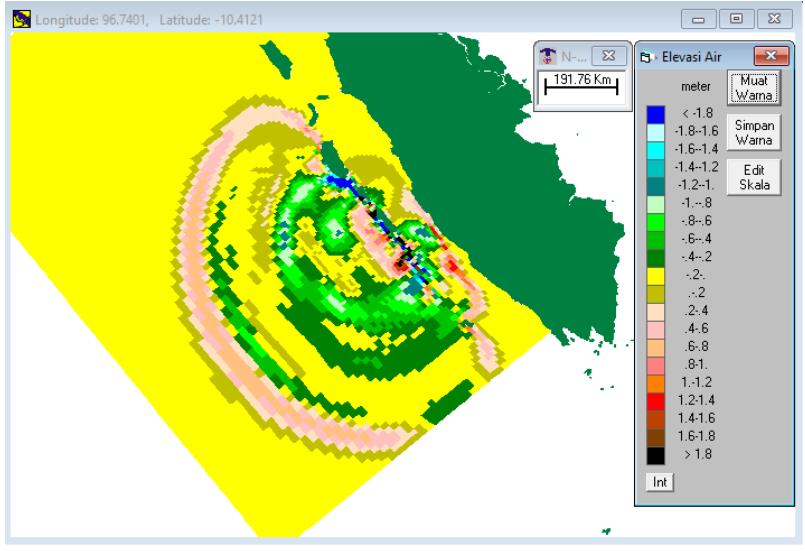

Fig. 13. Water elevation at 39 minute after earthquake, the model was run using Simple Energy Approach

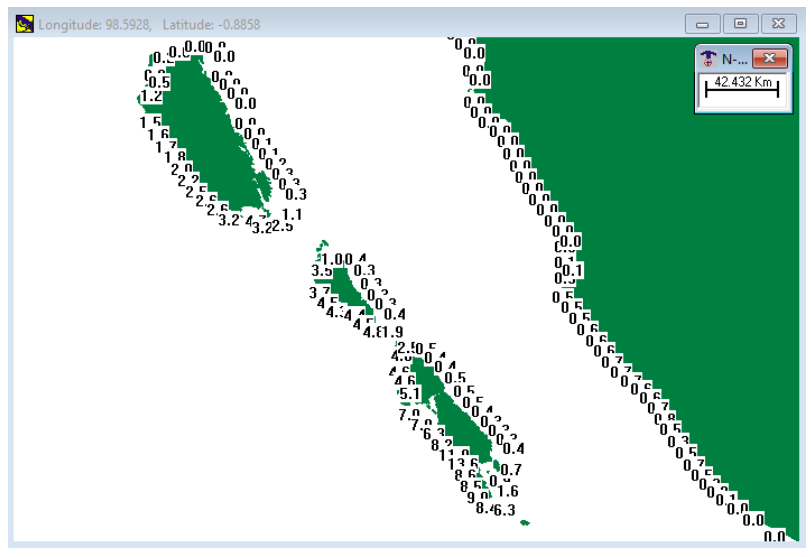

Fig. 14. Water elevation along West Sumatra Province coastal water, the model was run using Simple Energy Approach

Figure 11 to Figure 13 shows the results of simulation in quick response mode using simple energy approach at 16 minutes, 28 minutes, and 39 minutes after the initial condition respectively. The wave height along Aceh coastal area is shown in Figure 14. Clearly, the results of simulation are less accurate compare to previous simulation. However, the simulated wave is a worth information for quick response. The model does show correct impacted area.

\section{Conclusion}

Software MuTsunami, model of Tsunami propagation and sediment transport model using non-orthogonal curvilinear-coordinate technique in spherical coordinate as in house research tool of Tsunami simulation in CERG ITB had been applied for Mentawai Tsunami. The comparison between the modeling results and observation are very good.

Like in application of model in Aceh, the simulation results also shows that Simple Energy Approach for Tsunami Generation can be used as a preliminary simulation or for quick response as early warning although it will be less accurate. The impacted area is consistent with field observation. 


\section{References}

1. M. Muin, Ph.D. Dissertation, Department of Ocean Engineering, University of Rhode Island (1993)

2. M. Muin, M.L. Spaulding, J. Hydraulic Engineering 123, 13 (1997)

3. M. Muin, M. L. Spaulding, J. Hydraulic Engineering 123, 2 (1997)

4. S. Sankaranarayanan, Continental Shelf Research 25, 2233 (2005)

5. S. Zigic, O. Makarynsky, S. Langtry, G. Westbrook, Proceedings of the International Conference on Estuarine and Coastal Modeling 388, 428 (2010)

6. S. Sankaranarayanan, D.F. McCay, J. of Waterways, Port, Coastal, and Ocean Engineering 129, 114 (2003)

7. M. Muin, Dewan Riset Nasional Indonesia (1998)

8. M. Muin, A. Wurjanto, Proceedings of the Twentythird International Offshore and Polar Engineering (2013)

9. H. Yue, T. Lay, L. Rivera, Y. Bai, Y. Yamazaki, K.F. Cheung, E.M. Hill, K. Sieh, W. Kongko, A. Muhari, J. of Geophysical Research: Solid Earth 119, 5574 (2014)

10. T. Mikami, T. Shibayama, M. Esteban, K. Ohira, J. Sasaki, T. Suzuki, H. Achiari, T. Widodo, Natural Hazards 71, 851 (2014)

11. M. Muin, Manual MuSed3D and Technical Guidance, Ocean Engineerng, Institut Teknologi Bandung (2001)

12. S.T. Grilli, P. Watts, J. of Waterway, Port, Coastal, and Ocean Engineering 131, 283 (2005)

13. F.E. Camfield, Chapter 10 Handbook of Ocean Engineering (1992)

14. M. Muin, M.L. Spaulding, J. Hydraulic Engineering 122, 512 (1996)

15. M. Esteban, V. Tsimopoulou, T. Mikami, N.Y. Yun, A. Suppasri, T. Shibayama, International Journal of Disaster Risk Reduction 5, 84 (2013) 